\title{
Maria di Francia, Favole
}

\author{
Maria Colombo Timelli
}

\section{(2) OpenEdition}

\section{Journals}

\section{Edizione digitale}

URL: http://journals.openedition.org/studifrancesi/9424

DOI: ERREUR PDO dans /localdata/www-bin/Core/Core/Db/Db.class.php L.34 : SQLSTATE[HY000]

[2006] MySQL server has gone away

ISSN: 2421-5856

\section{Editore \\ Rosenberg \& Sellier}

\section{Edizione cartacea}

Data di pubblicazione: 1 décembre 2007

Paginazione: 625-626

ISSN: 0039-2944

\section{Notizia bibliografica digitale}

Maria Colombo Timelli, «Maria di Francia, Favole», Studi Francesi [Online], 153 (LI | III) | 2007, online dal 30 novembre 2015, consultato il 08 janvier 2021. URL: http://journals.openedition.org/studifrancesi/ 9424 ; DOI: https://doi.org/ERREUR PDO dans /localdata/www-bin/Core/Core/Db/Db.class.php L.34 : SQLSTATE[HYO00] [2006] MySQL server has gone away

Questo documento è stato generato automaticamente il 8 janvier 2021.

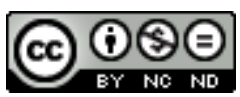

Studi Francesi è distribuita con Licenza Creative Commons Attribuzione - Non commerciale - Non opere derivate 4.0 Internazionale. 


\title{
Maria di Francia, Favole
}

\author{
Maria Colombo Timelli
}

\section{NOTIZIA}

MARIA DI FRANCIA, Favole, Introduzione e traduzione a cura di Roberta MOROSINI, Roma, Carocci, 2006 («Biblioteca Medievale», 104), pp. 176.

1 Questa prima edizione italiana delle Fables, con traduzione a fronte, appare sconcertante per più motivi. L'Introduzione, che si propone di fare il punto su argomenti che la critica affronta da decenni (l'identità dell'autrice, la tradizione della favolistica medievale, i temi e i personaggi della raccolta), poggia su una bibliografia prevalentemente anglo-americana, almeno a giudicare dai rinvii in nota, ma soprattutto contiene affermazioni poco documentate se non difficilmente sostenibili. Un paio di esempi: «Le opere di Maria di Francia riconducono al silenzioso, ma fervido, mondo intellettuale e poliglotta del chiostro dell'Inghilterra anglo-normanna, sia per la spiccata personalità di Maria, sia per la consapevolezza, non comune, del mestiere letterario» (pp. 11-12); e ancora: «Maria e i suoi contemporanei avevano una nozione alquanto vaga della traduzione» (p. 13). Che poi il successo della raccolta, testimoniato da 23 manoscritti conservati, si spieghi attraverso il fatto che «si riteneva la favola una forma letteraria per bambini» appare al contempo semplicistico e contestabile, tra l'altro per la mancanza di ogni precisazione cronologica, ma tanto più lo sarebbe se riferito ad un Medio Evo che, se pur ha prodotto una ricca serie di manuali per la scuola, anche per i livelli elementari dell'insegnamento, non sembra aver conosciuto la categoria della «letteratura infantile»; resterebbe comunque da dimostrare che le Fables fossero destinate alla gioventù.

2 La Nota alla traduzione (pp. 39-40) contiene altre affermazioni sorprendenti. R.M. informa ad esempio di aver «consultato tutte le edizioni delle Fables e in particolare Les Fables a cura di Charles Brucker» (p. 39). Si apprende poi che l'edizione fornita è quella di Karl Warnke (Halle 1898, ristampata da Slatkine nel 1974), basata sul ms. BL Harley 978, ma ci sfugge la ragione per cui - sempre a proposito della traduzione - siano di 
seguito elencati i quattro manoscritti che Warnke riunisce nel gruppo (alfa, e non A, come detto sempre a p. 39). Stupisce poi il candore di enunciati come «Per la mia traduzione ho consultato gli unici manoscritti miniati delle Fables...»: difficile comprendere il rapporto tra l'illustrazione di un codice e l'operazione traduttoria, tanto più che nemmeno nell'Introduzione si discute la tradizione della raccolta $o$ l'iconografia del testo. Scopo principale della Nota sarebbe naturalmente di render conto dei criteri seguiti per la traduzione: anche qui, però, ingenuità e generalizzazioni abbondano, mentre l'informazione viene a mancare; un paio di esempi: «Mi sono presa la libertà di cambiare quando e dove l'ho ritenuto necessario solo per rendere più scorrevole la lettura e mai con l'intenzione di 'correggere' Maria di Francia» (p. 39); «ho voluto rendere lo spirito di ogni favola cercando di non tradire il contesto del xii secolo e delle (sic) consuetudini sociali e politiche dell'epoca» (p. 40).

3 L'edizione è su due colonne, originale francese a sinistra, traduzione a fronte. Non sarà il caso di riprendere o discutere una per una le numerose approssimazioni ed errori nell'adattamento italiano; mi limito perciò alle primissime pagine: "Cest essample vus vueil mustrer» diventa "Questo esempio ci insegna che...", p. 52; "Altresì est del mal seignur», in italiano "Avviene lo stesso con i signori malvagi», p. 55; nella stessa pagina: «A une altre fisse requist / qu'en sun ostelet la suffrist» corrisponde a «Chiese ad un'altra cagna, scusandosi per il fastidio, di ospitarla nel suo alloggio»; ancora a p. 61, «Le pertuset ot fet petit» diventa in italiano «Aveva poi richiuso il buco»; mi chiedo infine come la coluevre di XVIII, 33 possa trasformarsi in una cerva nella traduzione italiana. Va rilevato che nemmeno il testo antico-francese è esente da errori: Prologus, 33 (m'en $a$ requise), II, 1 (Ci dit del lou, e non: del ou), II, 27 (Ja me fez tu ore cuntraire, e non: Je me fez ore c.), VII, 35 (demani, e non: demani), VIII, 3 (mes ne sot, e non: mes na sot), VIII, 13 (iesteit, e non: esteti), VIII, 21 (dune, e non: dune), IX, 21 (eliminare la virgola tra beals e celiers, correttamente tradotto belle cantine), XIII, 16 (Unc, e non: une), XV, 39 (que, e non: qua); nella Fable XVIII, De ranarum rege, il trunc più volte nominato (vv. 13, 15, 18) è trascritto trune, calco su «trono» dal momento che si parla di un re?

4 Non si può onestamente dire che le Favole sono accompagnate da note: due, a p. 53 e a p. 69, spiegano che «Destino è personaggio femminile per Maria di Francia» (I). Le altre due sono più curiose: a p. 87, la nota 3 informa che nell'edizione Warnke mancano i due versi finali della Fable XXXI, il che corrisponde al vero; il couplet in questione, che non è riportato, risulta peraltro tradotto in italiano: quale ne sia la fonte non è dato di sapere. A p. 160, il problema è analogo: nell'edizione Warnke mancano infatti i versi finali della Fable XCIII, che qui sono editati e tradotti, ma la fonte rimane ignota.

Un'ulteriore curiosità: i numeri dei versi, indicati nelle testatine, non appaiono accanto al testo.

Conformemente alle abitudini della collezione, non c'è glossario, ma, forse, è meglio così. 